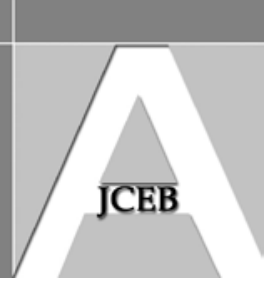

\title{
Perspectives on Modelling BIM-enabled Estimating Practices
}

Oluwole Alfred Olatunji (Curtin University of Technology, Australia)

Willy Sher (University of Newcastle, Australia)

\begin{abstract}
BIM-enabled estimating processes do not replace or provide a substitute for the traditional approaches used in the architecture, engineering and construction industries. This paper explores the impact of BIM on these traditional processes. It identifies differences between the approaches used with BIM and other conventional methods, and between the various construction professionals that prepare estimates. We interviewed 17 construction professionals from client organizations, contracting organizations, consulting practices and specialist-project firms. Our analyses highlight several logical relationships between estimating processes and BIM attributes. Estimators need to respond to the challenges BIM poses to traditional estimating practices. BIM-enabled estimating circumvents longestablished conventions and traditional approaches, and focuses on data management. Consideration needs to be given to the model data required for estimating, to the means by which these data may be harnessed when exported, to the means by which the integrity of model data are protected, to the creation and management of tools that work effectively and efficiently in multi-disciplinary settings, and to approaches that narrow the gap between virtual reality and actual reality. Areas for future research are also identified in the paper.
\end{abstract}

Keywords: BIM, BIM-enabled estimating, estimating, tendering

\section{Background}

Building information modelling (BIM) has had a critical impact on estimating practice in recent years. It is considered as revolutionary, relying on parametric and integrative capabilities to service multidisciplinary needs. Several different philosophical perspectives have emerged. Aranda-Mena et al. (2008) and Gu et al. (2007) argue that BIM is a precursor to revolutionary changes in prevailing professional practices and theories. Succar (2009) notes that BIM introduces new methodologies and provides the basis for new policies about how disciplines interact, collaboratively and cooperatively, in modern construction project delivery systems. Others have identified relationships between BIM and estimating processes, and how well construction projects perform. In this context:

- BIM databases are seen to facilitate objectivity as project teams collaborate and integrate data and processes across multiple disciplinary boundaries (Gujarathi \& Ma 2011).

- BIM offers project teams opportunities to communicate and collaborate in ways that are richer than in conventional processes (Aranda-Mena et al. 2009; Huang et al. 2009). Where communication and collaboration are compromised, Acharya, Lee and Im (2006) and Velasquez, Lara and Nof (2008) have shown that project performance suffers as a result of conflicts, errors and avoidable complications in the design and construction stages. These shortcomings may linger throughout facilities' operations.

Australasian Journal of Construction Economics and Building 2014. ( 2014 Oluwole Alfred Olatunji and Willy Sher. This is an Open Access article distributed under the terms of the Creative Commons Attribution 4.0 Unported (CC BY 4.0) License (https://creativecommons.org/licenses/by/4.0/), allowing third parties to copy and redistribute the material in any medium or format and to remix, transform, and build upon the material for any purpose, even commercially, provided the original work is properly cited and states its license.

Citation: Olatunji O.A. \& Sher W. 2014 'Perspectives on modelling BIM-enabled estimating practices', Australasian Journal of Construction Economics and Building, 14 (4), 32-53. http://dx.doi.org/10.5130/ajceb.v14i4.32 
- BIM improves the accuracy of estimates as well as of designs (Eastman et al. 2011).

- BIM does not address all the challenges experienced by those designing, constructing, maintaining and deconstructing buildings. Amor and Faraj (2001) and Amor, Jiang and Chen (2007) argue that it is technically impossible for BIM data to be structured to simultaneously satisfy the requirements of these disciplines.

- BIM enables disciplines to adapt and manipulate data according to their own requirements. Studies by Sattenini, Azhar and Thuston (2011) and Sattenini and Bradford (2011) indicate that BIM solutions vary from discipline to discipline and depend on the task at hand. This suggests that it is the prerogative of each discipline to explore how best to manage their BIM-specific solutions.

- In the context of estimating, a common simplistic view is that BIM data enable accurate estimates to be prepared (Eastman et al. 2011). However others argue that automatic estimating solutions may be based on the export of BIM metadata (Yum et al. 2008; McCuen 2009; Sabol 2008; Zhiliang et al. 2011).

These observations indicate the breadth of estimating-related applications that BIM impacts upon. BIM offers solutions to the numerous problems that beset traditional construction project management processes. This is not to say that BIM provides a silver bullet for all the challenges identified. The limitations of some of these solutions are indicated by the authors concerned.

Additionally, Holzer (2007) argues that estimating with BIM requires more than the adoption of model data by non-design professionals. Dean and McClendon (2007), Love, Edwards and Han (2011) and Tiwari et al. (2009) agree, arguing that it is not yet possible to automate estimating simply by exporting BIM data to other applications. Furthermore, BIM-enabled automated estimating is unlikely to entirely replace conventional estimating practices. Olatunji, Sher and Gu (2010) argue that BIM is likely to transform these traditional practices. They highlight the contribution that BIM can make in quantifying the materials and other construction elements of which buildings are comprised. They foresee an emerging reliance on BIM applications to generate such quantities, but argue that estimators still need to vet BIM-generated quantities. Furthermore, they predict estimators' responsibilities for costing and resourcing will continue. Despite the time BIM applications save in quantification, reliable estimates require some model reconstruction, design analysis and adaption to address the peculiarities of individual construction projects.

A significant challenge relates to the manner in which BIM data are structured. Amor, Jiang and Chen (2007) and Pučko, Šuman and Klanšek (2014) observe that these data are generally not organised in ways that meet estimators' requirements. Tiwari et al. (2009) and Olatunji and Sher (2010) suggest that overcoming this challenge is time-consuming; although others have pointed out that BIM-estimating improves estimators' productivity (Kim et al. 2009). Nevertheless there is debate about whether perceived productivity improvements are a substitute for accuracy, feasibility and thoroughness (Ogunlana \& Thorpe 1991).

Estimators have long been reluctant to embrace automated estimating solutions (Best et al. 1996; Brook 2004; Lowe \& Skitmore 1994; Ogunlana \& Thorpe 1991; Sher 1996). According to Hardie et al. (2005), this trend persists notwithstanding the proliferation of computer-aided estimating solutions that have evolved over the years. Cartlidge (2010) notes that there is general acceptance amongst construction professionals that estimators' skills cannot currently be subsumed by BIM-enabled systems. However, we argue that estimators should not be complacent about the changes BIM-enabled applications foreshadow. The pace at which these applications have developed over the past decade has accelerated and it is likely that that they will continue to evolve in increasingly sophisticated ways. Whilst BIMenabled estimating processes neither substitute nor replace traditional estimating approaches, it is important to distinguish between BIM estimating and conventional 
estimating. This paper explores how an analysis of BIM-enabled estimating activities can contribute to the development of contemporary theories and new directions. In turn, these facilitate comparisons with other design regimes. The following section describes the relationships between estimating processes and BIM attributes. It reviews literature about BIM-enabled estimating and explores the contributions of estimating activities and processes to construction businesses, and how BIM impacts upon them.

\section{Different Forms of Estimating}

There are various forms of construction estimating and these align with stakeholders' perspectives and priorities. Olatunji (2012) distinguishes between estimators who work in client organizations, contracting organizations, consulting practices and those who work in specialist project organizations. The approaches they adopt result in subtly different practices and procedures. Some of the nuances between these approaches are discussed below.

Construction contractors distinguish between their costs (their estimate) and the amount of money they are prepared to sell their work for. In cost accounting terms this is called their price (or tender amount) and includes sums of money that allow for site and general overhead expenses, risk allowances, contingencies and profit. Contractors prepare their estimates using various approaches. Some are based on predicting costs from first principles (including unit rate, operational rate and spot rate estimating), (Akintoye \& Fitzgerald 2000; Ashworth 2010; Ashworth \& Hogg 2007; Brook 2008; Gerrard 2000; Harris et al, 2006; Skitmore \& Wilcock 1994). Other approaches service the tenders prepared by sub-contractors for discrete work packages. Tendering (the conversion of an estimate into a profitable offer to complete a construction project) is far less well documented because contractors are loath to publicise details about commercially sensitive aspects of their businesses.

Clients require budgets from the very early stages of a construction project. Whilst these budgets may be prepared in-house or out-sourced, they are generally based on data from past projects. Frequently, these data relate to projects that were constructed in different conditions and circumstances to the current project. They reflect the approach adopted by a specific contractor, using their particular construction methods and overheads structure. Clients select suitable historic tender data and modify these according to current economic conditions and the peculiarities of the project in question. Some large clients and providers of estimating services collect their own data. These are sometimes supplemented by reference to published cost data (RICS 2014) and by market surveys. This pragmatic approach has become widespread amongst clients.

There is considerable potential for BIM to impact on the estimating practices of clients, their representatives and the professional consultants they employ, as well as on contractors, sub-contractors and suppliers. However, the term estimating has different meanings for clients, the professional teams they engage and the contractors who are called upon to complete the works on site. A client's view of a construction estimate is that of a contractor's tender, whereas for a contractor, an estimate and a tender are mutually dependent on each other. This is particularly relevant to discussions about BIM-enabled estimating because the variety of discipline specific interpretations inevitably leads to confusion. We have not distinguished between the estimating practices and procedure of clients and contractors in this paper because of the generic nature of our discussions. Readers are however alerted to these differences and the subtleties involved.

\section{Review of Related Studies}

BIM-enabled estimating is described as an automatic process that involves adopting and/or adapting data, exporting these and then associating them with costs based on past projects. Automation is not new to estimating processes: Skitmore (1990), Smith and Skitmore (1991), 
Best et al (1996) and Sher (1996) describe computer-aided estimating processes that existed before BIM. Many estimators use dedicated estimating software for BIM-related estimating tasks. However, sophisticated BIM processes and procedures do not necessarily result in accurate estimates (Olatunji 2014). Nonetheless, much can be learnt from the computer-aided estimating methods used prior to BIM and those that are BIM-enabled. These may be reviewed through the following lenses:

- Has anything changed?

- BIM capabilities and the quality of construction estimates: does parametricism make any difference?

- Process modelling: a critique of options

\section{Computer - aided Estimating: Has Anything Changed?}

The computer-aided estimating applications available before the advent of BIM generally replicated conventional estimating processes. For example, Best et al. (1996) reported that estimators have always used different software applications for different estimating activities - for quantification, resource planning, calculating costs, document management, risk analysis and contract management. As conventional CAD became popular, Geiger and Dilts (1996) suggested that estimators could exploit CAD data. These authors described the process of estimating with CAD as a quasi-integrated approach upon which subsequent computer-aided estimating approaches could be built.

Following Geiger and Dilts' (1996) work, several studies indicate increasing interest in integrated solutions for estimating. For example Gujarathi and Ma (2011), Pratt (2011), Peterson and Dagostino (2010) and Pučko, Šuman and Klanšek (2014) have all shown that quantification processes can be integrated with CAD and that the outcomes can be linked to cost databases. Various authors including Sher (1991) and Underwood and Alshawi (1997), have documented the development of computer-aided systems for integrating interim valuations and pre-contract estimates. These integrated processes are subtly different to the manual processes described by Ashworth (2010), Brook (2008), Collier (1974), Gerrard (2000), Harris et al. (2006) and Skitmore and Wilcock (1994). According to these authors, conventional manual quantification activities are fragmented and include taking-off, abstracting, working-up and drafting of bills of quantities. Each of these activities requires different resources and actions. When these activities are integrated, outcomes become streamlined. BIM-enabled estimating draws on the integration of design, measurement and estimating activities. Whilst many estimating applications have evolved to exploit BIM data, opinions about BIM-enabled estimating processes differ. Recent research suggests that BIM-enabled applications require approaches and skills that differ from conventional estimating methods. For example Dean and McClendon (2007) observe that estimators use fragmented tools to estimate with BIM, whilst Bailey (2010), McCuen (2009), Sabol (2008), Samphaongoen (2010), Yum et al. (2008), Zhiliang et al. (2011), Lawrence et al. (2014) and Pučko, Šuman and Klanšek (2014) all propose different BIM estimating methods.

It is informative to distinguish between these approaches and to appreciate the underlying differences (see Figure 1). In conventional estimating processes estimators regularly refer to the different rules and practices that govern measurement and estimating. Variants of these documents, including Standard Methods of Measurement (SMM) exist in different contexts (there are SMMs for building, civil works and for heavy engineering works) and geographic locations (including UK, Australia and South Africa). Whilst similar elements exist in different contexts, each SMM may provide different measurement rules. Ambiguities arise if components are ill-defined or not described in SMMs. Best practice guidelines (e.g. the CIOB's Guide to Estimating Practice) recommend that estimates are developed according to structured processes upon which cost and resource estimates are based (Seeley \& Murray 2001; Seeley \& Winfield 1998). 


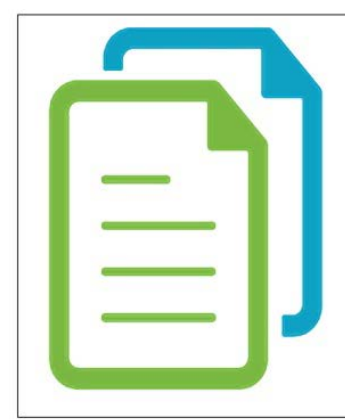

Measurement rules, quantification templates, data files, project drawings

In traditional estimating processes, estimators rely on measurement rules, which require strict interpretation irrespective of project situations. Even when digitizers are used, estimating processes have remained largely unchanged.

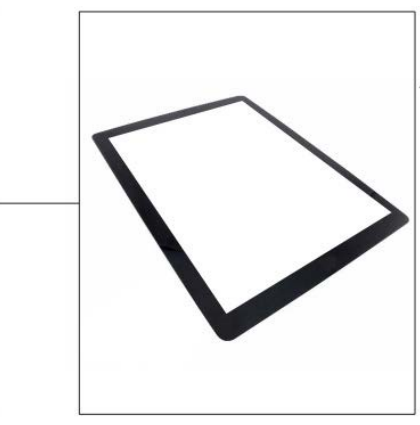

Digitizers, word processors, estorage

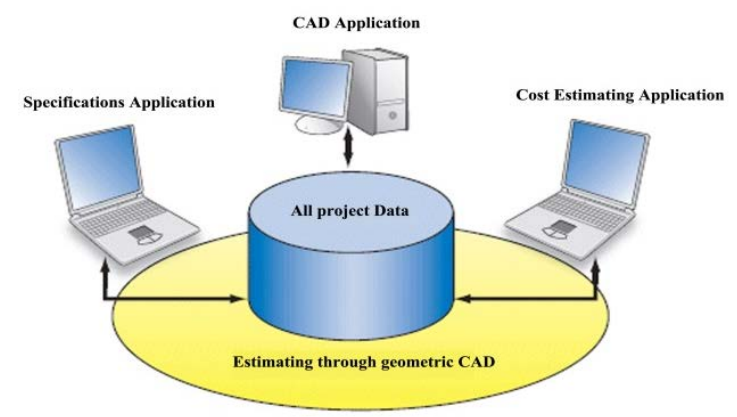

Estimating with CAD data - adapted from Dean \& McClendon (2007)

Using CAD data, estimating processes and methods have remained largely unchanged. Noticeable additions include automated data extraction from CAD files, development of rule libraries into quantification applications and integration of resource and cost databases with quantification data.

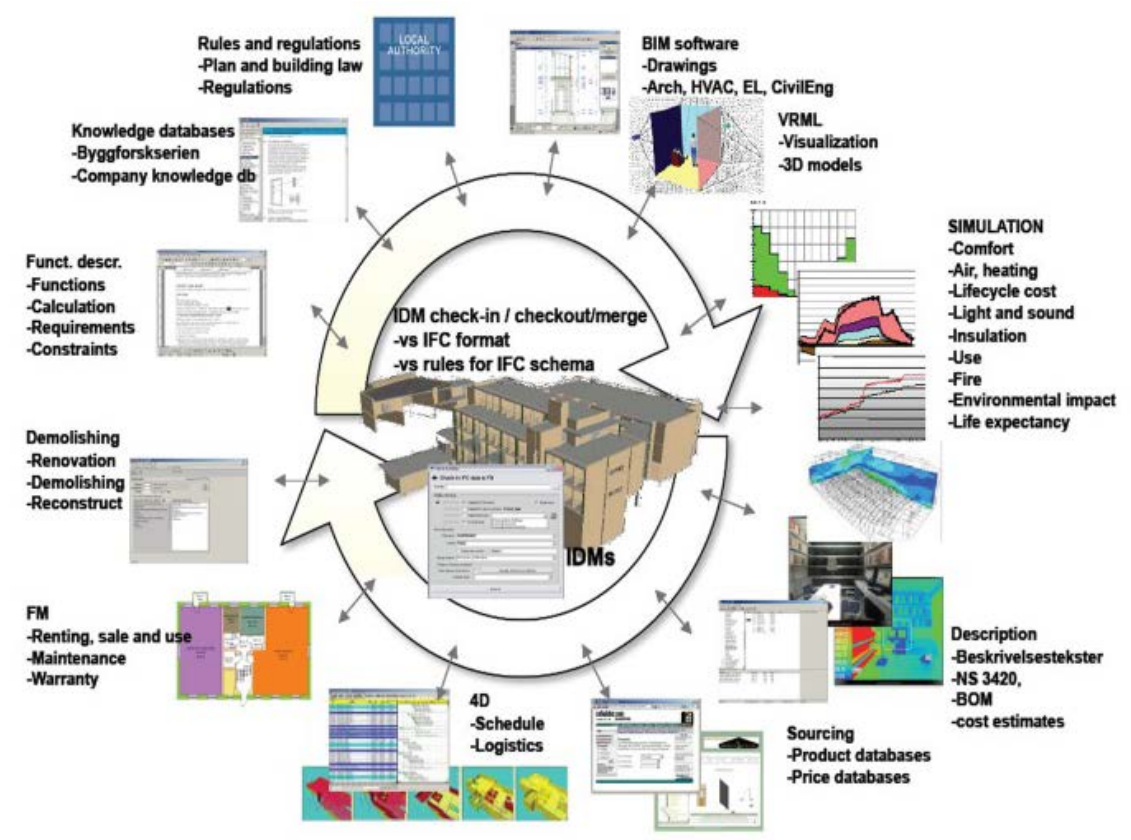

Integration in BIM/Parametric CAD regimes (Adapted from www.buildingsmart.org)

In BIM/parametric CAD regimes, context-specific data can be exported to different estimating applications or have cost data contained within a model. While other design regimes may be fragmented, BIM is able to integrate data across the different stages of a project's lifecycle.

Figure 1: A taxonomy of estimating systems in different design data structures 
Over the years quantification practices have evolved to exploit the opportunities presented by digital technologies. For example, there are applications that allow measurements to be generated directly from CAD files and others that allow digital scaling of hardcopy drawings. Moreover, when combined with relevant parametric performance data, estimators can quantify and cost construction drawings appreciably faster than when conventional processes are used (Sher 1982). Notwithstanding these advantages, some estimators prefer to measure manually from drawings. They are hesitant to change and prefer approaches that they consider to be tried and trusted. Although BIM builds on conventional 2D CAD, the estimating processes used in 2D CAD and BIM are different. Generally, estimating with 2D CAD replicates traditional processes, whilst BIM-enabled estimating provides additional deliverables. BIM data can be used to prepare estimates without substantial alteration (Tiwari et al. 2009; Yum et al. 2008).

Simulations can be developed with BIM data to show the sequence and duration of construction operations. It is also possible to visualize different construction sequences (Vozzola et al. 2009; Huang et al 2009). Sundry documents can be attached to BIM data (including technical notes, instruction manuals and operational manuals). These ancillary details or hyper-models may be stored in BIM databases and used, for example, to accumulate and record the lifecycle costs of a construction project (Olatunji 2012). BIMenabled estimating thus provides benefits that extend beyond design and construction. Recognising these benefits, some construction businesses have chosen to focus on BIM projects (Abdelkarim 2010).

\section{BIM Capabilities and the Quality of Construction Estimates: Does Parametricism Make any Difference?}

The main difference between 2D CAD and BIM is the ability of the latter to be altered when selected parameters are changed. According to $\mathrm{Ji}$ et al. (2011, p.1), "geometric representation... is restricted to explicit, extrusion and Constructive Solid Geometry (CSG) approaches". Hubers $(2010$, p.3) notes that "the advantage of parametric software is that if the virtual 3D model is set-up appropriately, changes in the parameters [will] generate within minutes[,] complete correct models and consequent bill of quantities and 2D sections (...) it [is] possible to adjust designs until the last minute".

Parametric design models are assembled from digital data that are linked by user-defined parameters. When one parameter is changed, the resulting impact is reflected automatically in all connected components. This means that the underlying data, which estimators rely on for quantification, represent the entire design model at a point in time. If measurements are exported as designs evolve, successive records can be harvested to show how costs have changed over time. Quantification data can thus be exported in forms that facilitate estimating and resourcing. Hubers (2010) refers to these data as bills of quantities. In his view, and contrary to other researchers (e.g. Amor et al. 2007), parametric BIM data are sufficiently well-structured to meet the requirements of estimators, including interpreting standard methods of measurement and commercial considerations that accompany estimating calculations (e.g. Ashley \& Teicholz 1977). In addition to Hubers' views, other researchers suggest alternative ways of developing estimates based on parametric data as described below.

\section{BIM Estimating Process Modelling: a Critique of Options}

Despite numerous case studies on BIM-enabled estimating (Broekmaat 2008; Dean \& McClendon 2007; Goldberg 2007; McCuen 2009; Zhiliang et al. 2011) there is little specific guidance about the use of these applications. Our study has identified the following four types of BIM-enabled estimating.

- The IFC export approach: BIM data need to be exported to dedicated estimating software applications. These data need to be structured in an application- 
independent format such as Industry Foundation Classes (IFC), exported to a spreadsheet and filtered to support specific reporting structures. Figure 2 shows a model for a multi-storey building as well as data to be exported to a spreadsheet. Rather than manipulating model data, this approach allows estimators from different domains to moderate the model data as they see fit.

In a case study reported by Ma, Wei and Zhang (2013) algorithms were created to export and filter IFC data to align with project specifications and other constraints. The results of this study indicate that BIM data need to be moderated to align with the specifications and the form of contract used. Zhiliang et al. (2011) conducted a similar study to Ma et al. (2013): they were able to translate IFC data directly into bills of quantities. However, it is unclear from these studies whether estimates can be reliably generated on the basis of BIM data. Each construction project is unique and generalised data need to be manipulated to cater for site specific constraints. The methods by which one-off element descriptions are catered for is presently not well documented. In addition, the process of transferring data between software applications is frequently problematic (Ji et al. 2011) as some IFC translators may not cater for unstandardized or unlinked components of models.

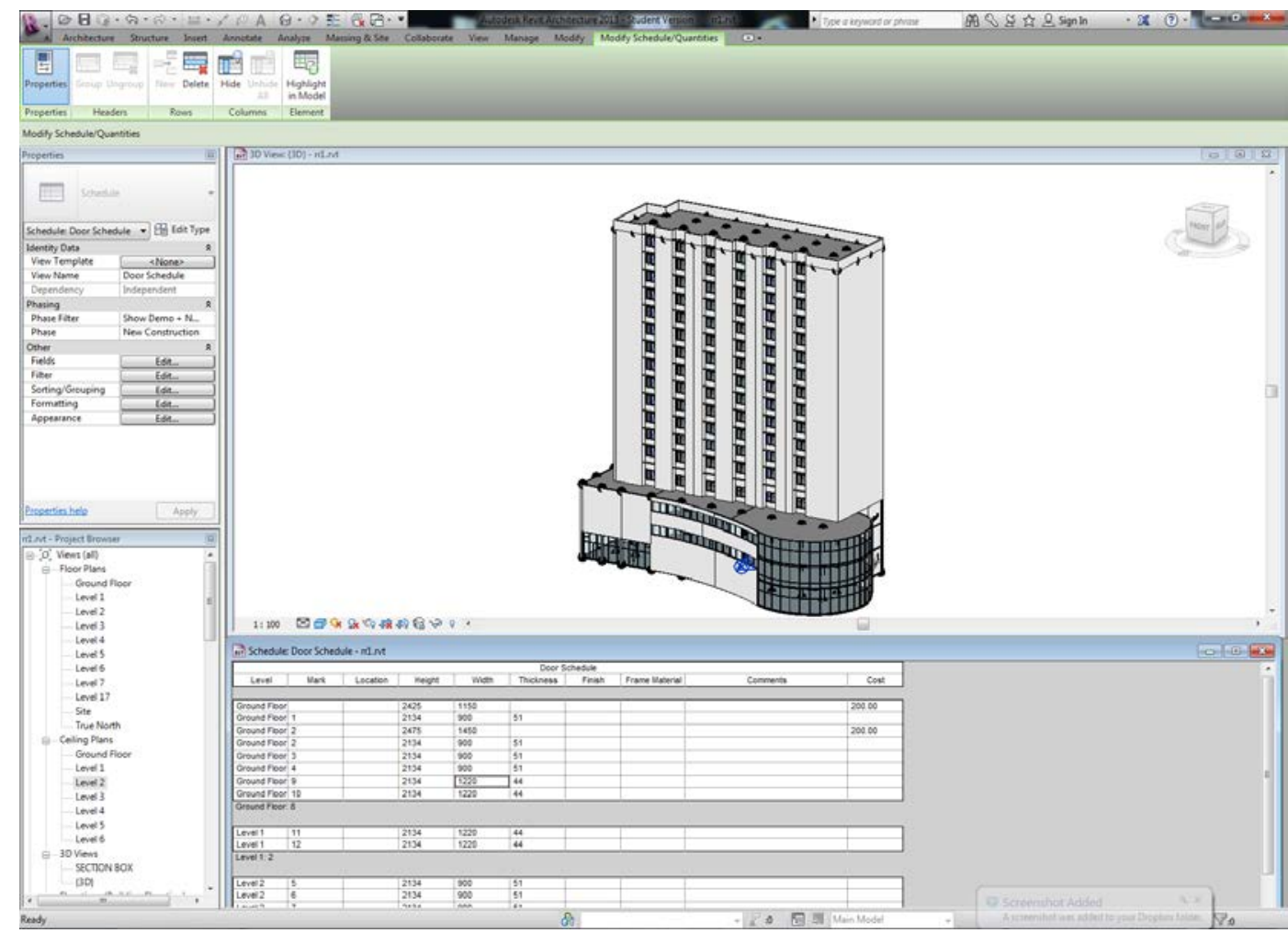

Figure 2: IFCs and model element data

- The model 'as-is' costing approach: Yum et al. (2008) proposed a procedure in which cost data were built directly into a design model. Using this approach BIM data store both cost and time components. Figure 3 shows how costs for doors are included in a model. Using this approach, every component is identified and costed without being exported to or manipulated in other applications. This approach can also be extended to generate forecasts of cash flow and timing.

Estimators' skills and abilities in this area are evolving. Issues relating to the reliability of model data for estimating purposes continue to raise concerns. For example, an element (e.g. a floor) needs to be modelled differently depending on whether it is flat or sloping. From an estimator's perspective different areas such as these require 
different resources, which in turn generate different costs. However, from a design perspective, such additional modelling is not commonplace. It follows that elements used for estimating purposes are unique (Olatunji, Sher \& Gu 2010).

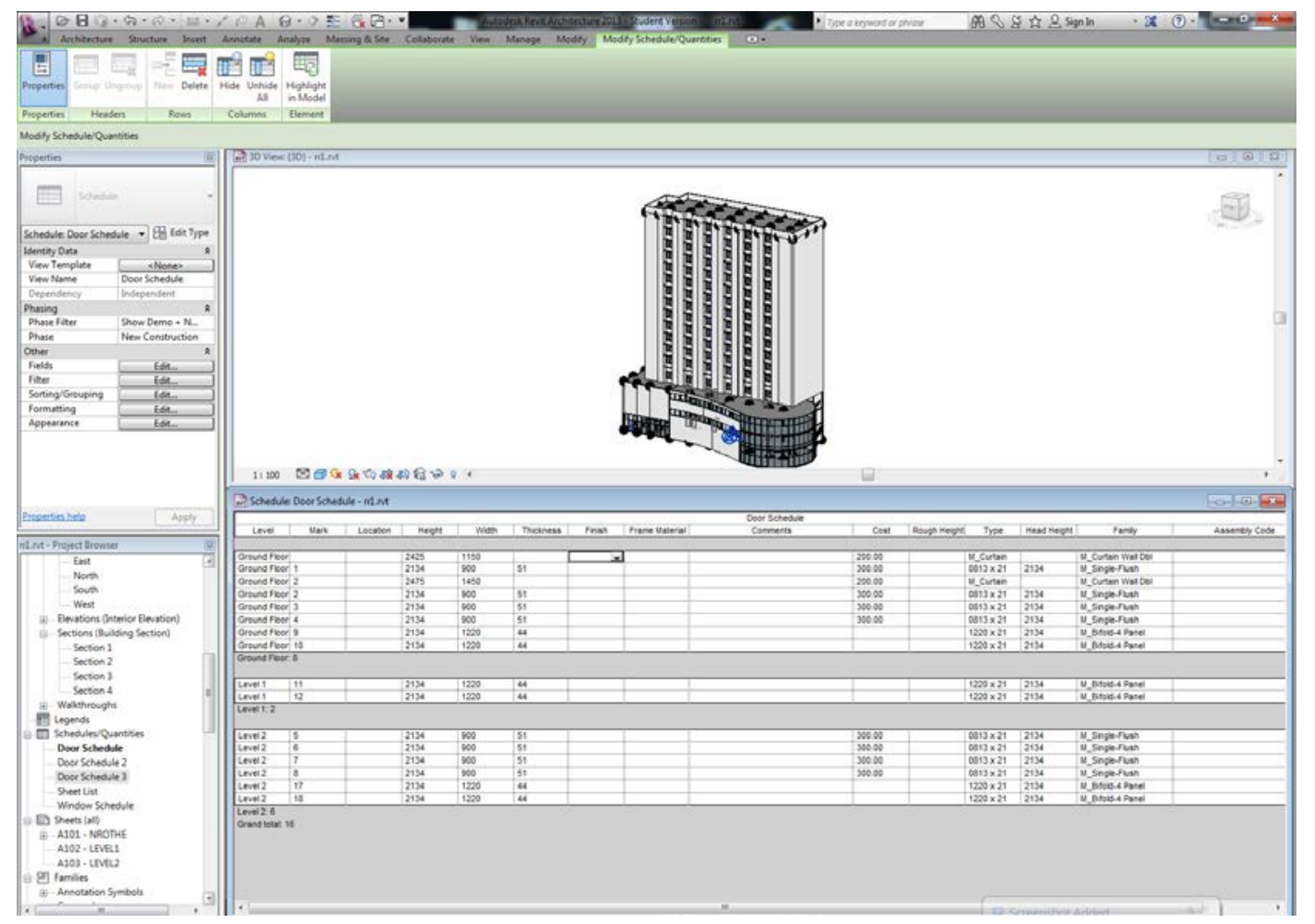

Figure 3: Embedding costs into models.

Based on the challenges described above, estimators would benefit from acquiring skills and abilities to interrogate and modify 3D objects. However there are few incentives for them to do this. They are discouraged, in part, by the lack of opportunities they have to influence the manner in which designers assemble 3D objects, and by the effort required to acquire such skills and abilities. In addition, dedicated model translators have been developed to convert BIM data into formats such as bills of quantities that are widely used by estimators (Pučko, Šuman \& Klanšek 2014). Where such translators are available, estimators see little benefit in developing the aforementioned skills and abilities.

An additional constraint is the one-off nature of this estimating approach. Each object needs to be uniquely resourced and costed and this contrasts with the structure of many computer-aided estimating applications. These facilitate the re-use of element specific resource data (and allow them to be adapted to the requirements of specific projects).

In summary, estimators are not designers and have few opportunities to influence the ways in which object data are assembled. This leads them to adopt pragmatic approaches to harvest the data prepared by others. An inevitable consequence of this is that they need to manipulate these data so that their needs are met.

- The model moderation costing approach: Estimators seldom adopt model data without review (Tiwari et al. 2009). This frequently leads to a restructuring of the data to reflect the estimating approaches adopted (e.g. construction processes, work zones, trades, project elements) (Amor, Jiang \& Chen 2007). Different estimators use different approaches to moderate models according to Olatunji (2012). Tools like Navisworks enable models that are generated in different applications to be merged. 
These tools facilitate design analyses, reviews, clash and interference detection and the ability to interact with the functional attributes of each element. Some of these tools also allow users to modify models without compromising their geometrical integrity. For instance, a large concrete slab, authored as a single element, can be divided into pours (see Figure 4 - note the light green area in the slab model). As such, all model elements can be broken down according to how they will be resourced and executed. These data can then be exported into dedicated applications for further estimate-related processes and analyses. However, this approach has some limitations. Integrative platforms generally limit the extent to which those who have not authored data are able to make modifications. Where modelled data are ambiguous, multiple disciplines may need to be involved to reach a resolution. However, clients can be exploited where such interactions are not possible (e.g. where a contractor shares a fragmented relationship with a project team, especially during bidding (Ashley \& Teicholz 1977).

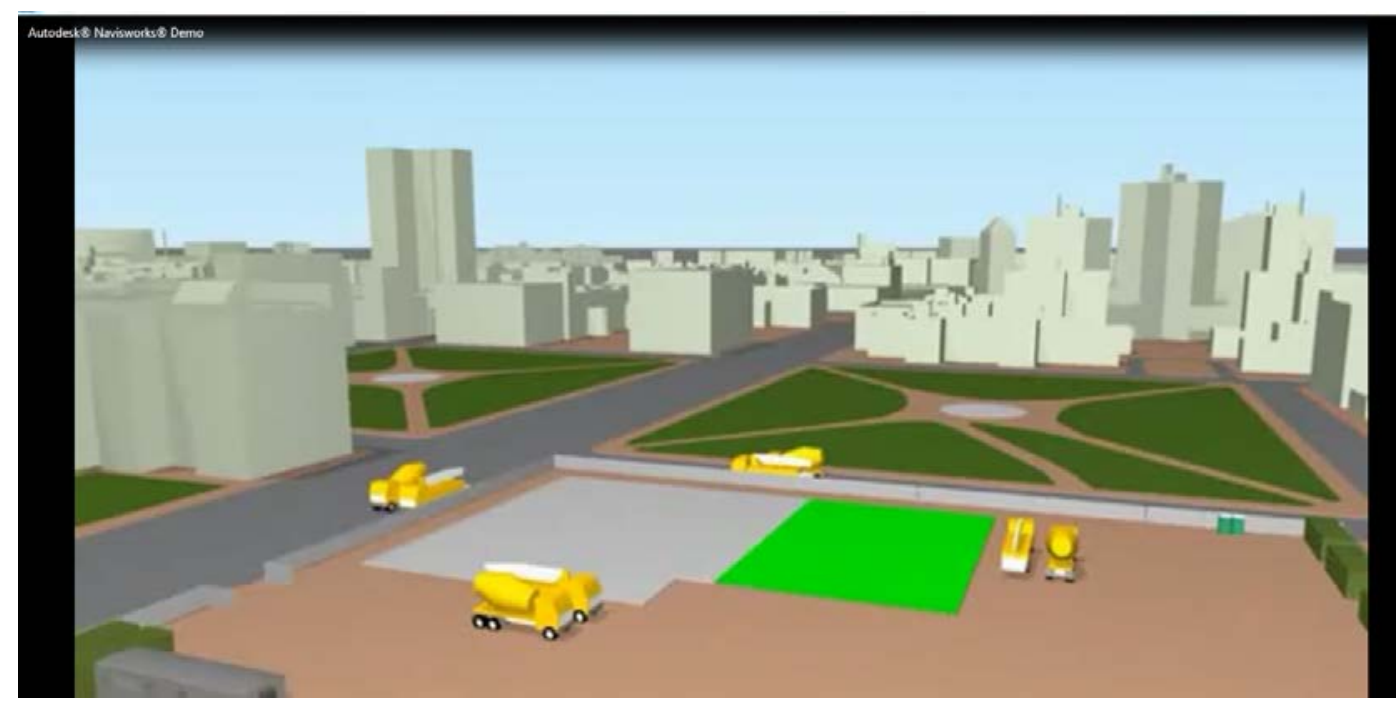

Figure 4: A slab model showing pour 'cut' (in light green)

- The process simulation costing approach: Estimates can also be based on simulations of the sequence of construction operations. Huang et al. (2009), Chou (2011), König, Beißert and Bargstädt (2007), Vozzola, Cangialosi \& Lo Turco (2009) and Yan (2008) have all experimented with this approach, but their conclusions vary. The overarching principle is that different construction scenarios may be simulated from a given design model but, in some of the aforementioned cases, the simulation tools used were not able to reflect resources appropriately. Furthermore, it is complex to incorporate risks into the process models and subsequent simulations. Although these process models are helpful for estimating purposes, it is noteworthy that they are not yet accepted as contract documents (Olatunji 2014). Contractors are those responsible for selecting construction methods and are therefore best placed to develop such virtual reality models. Consequently, the simulations prepared by other parties should be considered as indicative or advisory.

These approaches indicate that the challenges of estimating in BIM-enabled environments have evolved in a variety of ways. BIM-enabled estimating necessitates the management of data. It involves a consideration of what model data to export, how to work with these data, how to protect the integrity of the data, how to create and manage tools that work effectively in multi-disciplinary settings, and how to represent construction processes authentically in digital simulations. However there is currently little empirical evidence about these approaches. The goal of the investigation reported in this paper is to explore BIM-enabled 
estimating activities and their relative importance from the perspectives of estimators in each of the practice domains noted above.

\section{Research Method}

As described above, estimating may be ontologically stratified into different practice domains (Olatunji 2012). These are informative because they facilitate an understanding and appreciation of the imperatives faced by different construction professionals. Whilst the concept of predicting costs from digital data is attractive, there are significant challenges associated with this seemingly mechanical task. Extracting the quantities of building elements from digital models is only part of the challenge that estimators face, as data needs to be arranged in useful and usable ways. Once this has occurred, monetary amounts need to be associated with these quantities. The construction professionals responsible for calculating costs (estimates) and sales (tender) amounts do so in markedly different ways. In addition, and within the same practice domain, some estimators are likely to be more experienced and successful than others. Skitmore and Wilcock (1994) have shown that variability in estimating processes and outcomes is common in construction businesses.

This study has been designed to explore how estimators in different practice domains have embraced BIM estimating processes. We selected an equal number of firms to represent four practice domains. For the sake of simplicity and to facilitate triangulation of data, two firms (eight in all) were recruited to represent all the domains. Each firm nominated participants to contribute to focus group discussions and individual interviews both of which used semi-structured prompts. Seventeen participants took part in five focus group discussions and four interview sessions. Eighty eight per cent had worked as quantity surveyors and construction estimators for an average of over 22 years. They had worked in more than ten countries including Australia, United Kingdom, Singapore, Malaysia, Vietnam, Fiji and Brunei. Where participants were not estimators, they had worked in project management roles with estimators, and were conversant with BIM and BIM-enabled estimating applications. Participants had professional backgrounds in architecture, construction estimating, software engineering and quantity surveying. The University of Newcastle's ethics committee approved these investigations (Approval number $\mathrm{H}-2009$ 0275). The entirety of these investigations is reported elsewhere (Olatunji 2012). Participants were asked to explain or demonstrate how they estimated and planned in BIM-enabled environments. Their responses are discussed below.

\section{Outcomes}

Responses from these interviews were classified in the following five categories:

- Project conceptualization and design planning

- 3D visualization and virtual reality

- Automated estimating, hyper-modeling and tendering

- Contractor selection through virtual models and estimating during construction

- Post-construction estimating and using estimate data for facilities management

It is informative to consider these categories in the context of the RIBA Plan of Work stages (RIBA 2013) (Table 1). It will be noted that the categories identified from the interview data straddle the RIBA stages. This arguably highlights the need for protocols that explicitly encompass BIM-enabled practices. Nevertheless Table 1 highlights where BIM-enabled estimating practices align with the RIBA stages of construction and these are described and discussed below. 
Table 1: Research stages mapped against the RIBA Plan of Work (RIBA, 2013)

\begin{tabular}{|l|l|l|l|l|l|l|l|}
\hline $\begin{array}{l}\text { Strategic } \\
\text { Definition }\end{array}$ & $\begin{array}{l}\text { Preparation } \\
\text { and Brief }\end{array}$ & $\begin{array}{l}\text { Concept } \\
\text { Design }\end{array}$ & $\begin{array}{l}\text { Developed } \\
\text { Design }\end{array}$ & $\begin{array}{l}\text { Technical } \\
\text { Design }\end{array}$ & Construction & $\begin{array}{l}\text { Handover and } \\
\text { Close Out }\end{array}$ & In Use \\
\hline Stage 1 & Stage 2 & & & & & \\
& & & Stage 3 & & Stage 4 & & \\
& & & & & Stage 5 & \\
\hline
\end{tabular}

\section{Stage 1: Project Conceptualisation and Design Planning}

Participants saw BIM-enabled estimating starting with understanding clients' requirements in line with their project goals. The challenges experienced by some estimators at this stage are highlighted in the following quote:

'Many clients can't read plans. They might think that they can. A lot of architects can't read plans very well either. The main benefit of $3 D$ BIM is that clients understand the building better which gives them more realistic expectations of what they're getting'

Clients need to communicate their requirements to those they have appointed. However, the difficulties of appreciating three-dimensional spaces are apparent in the quote above. In addition, each project team-partner needs to align their understandings with those of others.

Some of the activities that occur during this stage are reflected in the quote below:

'....if you just get the raw dump of data from a $3 D$ file with everything inside, that information is useless. Quantities have to be organised in what we call a cost plan situation, a format that makes sense. The cost of a building can be dissected into elemental areas to be analysed...'

Bearing in mind the multiple different uses to which they are put, BIM data need to be manipulated before they are useful to estimators. The participants noted that models had to be reconstructed into elements that made sense before they could commence estimating. This involves reorganising the data so they depict a particular style of reporting (e.g. construction trade, section, element, zone or process). If, for whatever reason, estimators do not wish to reorganise their data, they can resort to condensed costing (explained in Stages 4 and 5). However, if estimates are to reflect all the activities involved in the construction process, some remodelling is required. This can occur, for example, where temporary works such as scaffolding and/or falsework are required. These items are integral to many construction operations and are removed once their temporary purpose has been accomplished. Designers generally do not represent these items in their models.

Estimators need to be able to visualize project elements and analyse how these elements interact. They need to be able to visualise construction processes and other project components. These aspects were emphasized by a participant who noted that estimators want to be

'... able to quickly look at different morphing of the building shape and configuration so that we can immediately give the architect and the rest of the design team some indication as to how it's affecting the budget.'

In this quote, underlining has been used to emphasize the fact that estimates should reflect the intended construction processes. This implies that estimates need to be appropriately resourced and accurately modelled. Many of the participants reconstructed their model data to reflect cash flow targets, cost plans and how they intended to structure their tenders. 
In summary, the estimating activities in this stage include:

- Interaction with the client and the project team.

- Model reconstruction to reflect the construction approach on which the estimate is based.

- Appreciation of the complexities of design components to enable costings to be calculated as accurately as possible.

- Design analyses, including clash detection, interference and value analyses of model elements.

- Resource planning and estimating for each building element.

- Export of data for ancillary uses.

Understandably, participants in the different practice domains attached varying degrees of importance to these tasks. For example, those in client-related organizations tended to focus on representing their clients' requirements and paid little attention to how the project was to be constructed. In contrast, understanding the constraints of a particular project from buildability and constructability perspectives was of prime interest to those representing contracting organizations. In this context it is interesting to contrast the priorities of construction professionals. Those in consulting practices discharged their services as umpires acting between their clients and contractors or by addressing the needs of the parties who employed them. The estimators in specialist project organizations were generally interested in the long-term goals of their projects. As this involved minimizing longterm risks, they often concentrated on design analyses that enhanced both product and construction process models.

\section{Stage 2 - 3D Visualisation and Virtual Reality}

Participants in client organizations observed that estimating using virtual reality (VR) starts with scenario simulation and uses active agents as described below:

'Virtual walk-throughs ties in with the client being aware. Adobe has in their free reader, the ability to view $3 D$ files which can be spun around. They can also be cut in a section and that section line can be adjusted in any plane and moved along. Clients love it. It means they can understand something. It's simple for them to use. They don't need proprietary software and it's quick. Designers can send them a plan. They can see where their office is and they can walk through that with no hassles at all'.

Based on the interviews, the estimating variables relating to $3 \mathrm{D}$ visualization and VR may be summarised as:

- Facilities use scenario simulation, using active agents to demonstrate clients' requirements so that informed choices can be made about priorities during design and procurement.

- Construction scenario simulations which show how construction activities are sequenced. This approach may be used as a basis for bid competition on large and highly risky projects. This is closely related to the construction contexts already established in Stage 1.

- Cost control: Design and project costs based on simulated models can be controlled according to targets. While clients usually focus on controlling the total cost of projects, from a contractor's perspective, production cost control is a priority. For integrated project delivery (IPD) projects the focus is on the long-term value of a project in preventing wastage, avoiding risks and promoting community engagement. In summary, different stakeholders have different perspectives on cost control at this stage (and use different tools to achieve their desired outcomes). Clients may focus 
on cost reduction, while contractors and IPD stakeholders focus on making a profit and providing value for money respectively.

- Model-based value engineering: based on scenarios of a facility's use and construction, these facilitate the integrated use of knowledge to inform decisions on value-adding designs and procurement alternatives.

- 4D, 5D, VR and hyper-modeling: 4D involves attaching a timescale to a 3D model. $5 \mathrm{D}$ is based on $4 \mathrm{D}$ plus an overlay of costs. VR involves simulating the use of a facility or its construction. Hyper-models are formed when non-geometric data are linked to a model. These documents include technical notes (for example, handling instructions about components and notes about risks).

- Finalizing project models for estimating and tendering: Modelers seldom construct models specifically for estimators. Consequently, estimators have had to adopt different design models and then deconstruct and reconstruct them to generate models that support the outcomes they require.

Participants had differing views about the importance of these activities. For example, participants in client organizations had a good understanding of hyper-modelling but made little use of these facilities (and were still able to prepare reliable estimates without them). Moreover, as clients generally do not specify a particular construction approach, participants representing clients did not ascribe high importance to construction scenario simulations. Instead, they focussed on use scenario simulations, although it was observed that they were able to complete their estimating processes reliably without committing much effort to these activities. It is interesting to contrast these views with those of participants in contracting organizations. Unless contractors' estimators are involved in model development, they focus on devising construction methods during pre-contract estimating. 3D visualization and VR was seen to provide contractors with a competitive edge and participants in contracting organizations viewed this activity as most important. As consulting practices serve the goals of their employers, participants in this domain viewed these activities in a similar way to clients' representatives. Although estimating using model objects was not found to be widespread, all the activities that occur were considered to be crucial to developing reliable estimates. Participants in specialist-project organizations also ranked all of these activities as very important.

\section{Stage 3: Estimating and Tendering}

All participants agreed that traditional estimating practices prevail. They are largely paperbased, and make minimal use of CAD. This applies whether or not data are sourced from CAD models. Participants identified the following four approaches:

(a) Data are exported to spreadsheets and then adjusted and re-arranged to prepare estimates of cost, time and tender price.

(b) Using applications such as Navisworks and VICO to remodel project model data, work items can be exported or interrogated in a variety of ways (based on location, time-lining, trades, sections or elements of buildings).

(c) Using translator applications such as CostX, models' descriptive data can be exported automatically into bills of quantities templates.

(d) Using simulation applications such as Synchro, it is possible to extract process representations according to estimators' preferences.

There was limited agreement about what should be presented in virtual process representations (d). Are these representations unique to BIM estimating or a continuation of activity-based construction (ABC) estimating? The following comment provides an answer to this question: 
'You push a button and quantities are generated. ... if [drawings are] in 2D it is not as easy to visualise if you do it in 3D, but even better if you've got BIM. You can virtually measure all the elements... You can pick up all the dimensions rather than measuring it. If you've got a wall, you don't have to measure it. If you want internal walls, external walls and everything else it would still be a lot simpler if we have got BIM information... It would be a lot simpler to measure and once it's measured, you know it's accurate because it's been produced using BIM functions. So we spent less time measuring, more time evaluating and helping to formulate the way the project should be going. The counter argument to the [one button] is that when you are stepping through the measurement process, you are coming to understand the building ... If you are just presented with a file and you press a button and all these quantities come out, you are no wiser than five minutes previously...'

The tasks at this stage were seen to include:

- Automatic export of BIM data in a format that can be imported into computer-aided estimating (CAE) systems.

- Moderation of model data e.g. timeline simulations and evaluated risk assessments (ERA) with a focus on specific project components which may be arranged as line items, elements, zones, locations, sections, interim report stages and finance engineering.

- Construction process hyper-modeling, including parametric resourcing and costing by ERA, and by focusing on prevalent market conditions in relation to customized construction method designs.

- Application of base costs for conceptual budgeting, including provisional estimating and market surveys.

- Conversion of estimates into tenders.

- Tender documentation, including augmented packaging and submission.

BIM-enabled estimating allows quantification data be exported to CAE platforms. Participants saw this activity as crucial. However, different practice domains used these data in different ways and these necessitate specific export protocols. Whilst estimators representing clients used translators that ensured that BIM data were costed as they appear in the model, contractors' estimators required more flexible solutions. These estimators need to predict the costs of successive construction operations and implicit in this is a consideration of specific items of plant and equipment and/or other resources. Quantification data therefore needed to be manipulated to align with the construction processes (rather than the model). This did not preclude clients' estimators from augmenting model data for their estimating activities (including conducting risk analyses, cost analyses related to different construction methods and predicting project cash flows).

Participants also appreciated the efficacy of process hyper-models to support estimates, as visualisations were considered to be more informative than texts. Whilst clients' estimators may focus on product data models, participants agreed that process hyper-models provided contractors with a competitive edge. Participants representing clients were receptive to visualizations of their project at time of tender. The following are the different ways this might occur

- Clients' estimators could simulate the costs of major project elements using short video clips, or show project development processes in their entirety. These clips could be used to stimulate discussion about alternatives and/or as a means of reviewing progress. 
- Contractors' estimators could create process hyper-models as short video clips and supply these with their tender documentation. These could be further developed after contract award in collaboration with clients and updated as the project progresses.

- Consultant practices could create similar video clips to help their clients visualize the cost implications of their decisions. These were seen to be useful in helping reconcile clients' requirements with the provisions made by contractors.

- Most specialist project organizations would prefer to have both their preliminary and detailed process models developed in collaboration with their main contractors from the start. Updating could be conducted collaboratively and/or cooperatively.

In summary, clients' estimators viewed the automatic importing of BIM product data to their applications as highly important. Estimators from other domains need to manipulate BIM data before using these in their CAE applications. They saw value in hyper-modelling and model reconstruction. Moreover, while clients' estimators considered auto-pricing based on past project data as highly important, other domains favoured costing by ERA, prevalent market conditions and customized operational process benchmarks.

\section{Stage 4: Contractor Selection Based on Virtual Models and Estimating}

Approaches for selecting contractors have remained unchanged for decades (Aje 2012). These involve checking for errors and discrepancies in bids. Most importantly, they rely on price and descriptive data in contractors' submissions to judge whether the clients' terms and conditions have been met. Participants felt that BIM assists this activity as follows:

'Many clients can't read plans... The main benefit of 3D BIM is that clients understand the building better which gives them more realistic expectations of what they're getting.'

Thus, instead of traditional paper-based estimate submissions, BIM makes it possible to use virtual construction process models to help clients visualize and analyse proposed construction methods.

'...So the idea is via an iterative process or via looking at and changing and varying the material structure of the building and also varying the operational energy considerations involved with operating the building. We can compare it to other buildings and also then we can make judgements as to how the construction will go.'

As noted above, estimators use different approaches to explore and exploit BIM data. On the other hand, clients need to specify the approach they require to be incorporated in their bids. Contractors commented that they supplemented their traditional bids with BIM-enabled digital resources and incorporated these into their contract documents in the following ways:

- Object pricing: Cost data can be included in an object as: the predicted costs of an object, notes on negotiations where applicable, actual construction costs, notes on procurement specifications, guides and embellishments and notes on amendments and change decisions.

- Object pricing of process hyper-models: In contrast to the above, where prices are embedded in models, hyper-models allow for the inclusion of resources and durations.

All participants agreed that augmenting tender submissions with BIM-enabled process models was valuable; $68 \%$ of participants had won large projects using this approach, or had participated in bids where BIM was used. In all these cases, the contractors spent 'obvious' additional costs on bid documentation. However there was no significant change to clients' tender costs. Participants also noted a $65 \%$ saving of the time they would have spent on quantity calculations when data were exported directly to their preferred CAE application. 
However the time spent developing hyper-models to support bids was difficult to assess and was seen to be dependent on the competence of the operator and on the application used.

Across all business models, participants indicated that the accuracy of their estimates did not change significantly when their estimates were based on BIM data. However, quantity measurement was faster, more reliable and more accurate than with 2D CAD. Thus, while participants could not quantify the extent to which BIM reduced costs, they argued that clients benefitted from the openness, control, project value and knowledge-based decisions that BIM facilitated. These intangible cost savings resulted from improved communication that was facilitated by BIM.

Participants were asked how BIM affected their tender analyses and selection of contractors. The consensus view was that BIM supported e-tendering but whether this was adopted or not, tender analyses and contractor selection were relatively unchanged from conventional practice; contract prices and contractors' values were seen as the main determining factors. In addition, participants commented on the contribution BIM made to tender analysis in terms of: automation (e.g. auto-reporting), error detection (e.g. omissions in model or item pricing, erroneous pricing and violation of bidding rules), and data management (e.g. whether data were transmittable, re-usable or error-proof). In all cases, BIM was seen to have had little impact on these issues. Although visualization helps decision-making, BIM had not replaced human judgment in selecting contractors. This involved reviewing bids and determining whether contractors were able to support BIM during construction.

Based on the above, BIM-enabled estimating activities at this stage include:

- Preparation of virtual representations of construction processes and alternatives

- Analyses of tenders based on visual, quantitative and qualitative data. BIM enables analyses of tender prices in tandem with life-cycle costs and values.

- Moderation/integration of work-process models to integrate client's models with those of contractors (e.g. to provide feedback on proposals, negotiations or to coordinate understanding).

- Organization of software applications to integrate on-site and offsite systems for cost management and project supervision purposes.

- Object-based communication (and analyses) of project finance matters. These replace text-based interim valuations, final accounts and accounts' reconciliations.

- Parametric documentation of a project's financial data, including embedding project models with valuations or actual project data, and reconciliation of a project's financial data.

Participants in clients' organizations viewed the use of virtual models for bidding and reporting as fairly important. Participants in contracting organizations observed that virtual representations helped them communicate the merits of their solutions. In addition, these also provided clients with opportunities to visualize and understand the choices they made. These participants noted that using BIM for tendering was a priority for some contractors, and that positive benefits had accrued from these activities.

While participants in clients' organizations viewed the integration of clients' and contractors' process models as important but not compulsory, estimators in contracting organizations preferred to interpret their clients' requirements in line with the strategies they chose. Representatives from consulting practices and specialist-project organizations supported the use of virtual representations and reporting. Although estimators in consulting practices identified some challenges (e.g. the lack of practice frameworks and the motivation of their clients), participants in specialist-project organizations thought that BIM adoption was selfdriven and its value was all encompassing. 


\section{Stage 5: Post-construction Cost Management and Facilities Management}

Unlike traditional practices where design, construction and facilities management data are fragmented, BIM enables these data to be integrated. Although some participants did not have extensive experience of facilities management, the information provided by others, especially those in specialist-project firms, was informative. Based on construction cost data, estimators still need to make decisions on taxation, depreciation of construction (and constructed) facilities, monitoring the cost implications of project performance and updating model data (as lifecycle phenomena) for maintenance works. The following quote is from a participant in a specialist-project organization:

'We operate a complete system; it allows us to do anything from early conceptual estimates through to full bills of quantities, through to progress claims, variations, financial reporting, tax depreciation, cash flows; we can all run it through this system and it all links together so you can carry a job basically all the way through from concepts through to basically tax and operational life cycle costings...'

Following earlier comments from participants in client organizations about database management, and in line with the quote above, it is evident that post-construction models contain cost information pertaining to when a project is handed over. When this is extended to facilities operations, the data can be used for lifecycle costing purposes. In addition, they can be used to update asset inventories and as auto-alerts when items require replacement or maintenance.

Based on participants' observations, the BIM-enabled estimating processes that support facilities management include integration of model data into asset inventories, the use of these inventories to track assets, providing management with intelligence for future procurement opportunities, consistently updated cost data in lifecycle product models and value analyses of space usage to inform future projects.

\section{Applications of Study Findings}

Participants viewed Stage 4: Contractor selection based on virtual models and estimating as the most value-adding stage leading to successful BIM estimating. Stage 3: Automated estimating and hyper modelling was ranked next, followed by Stage 2: 3D Visualization and virtual reality. The reasons for this can be ascribed to:

- New and unfamiliar skills being required to use VR. VR is not included in most professional and academic curricula and is not a mandatory requirement for most tenders.

- $\quad$ VR is a simulation tool. As such, what is shown on screen might not be what actually occurs. Thus, the correlation between VR and accurate estimates is debatable. Data from VR are neither exportable nor do they make estimating activities faster or more accurate.

Overall, participants viewed model decoupling, visualization and application of base costs as the most significant activities, while hyper-modelling, construction simulation and establishment of a basis for asset tracking were viewed as the least important. There are clear inferences to draw from this:

- Estimators found it difficult to manipulate BIM data to support their estimates.

- Visualization helps designers clarify their thoughts, reducing the need for guesswork due to uncertain design information.

- Estimators rely on historical data and these are contingent on the previous two points.

- Like VR, hyper-modelling requires new skills. Clients rarely require hyper-models and there is therefore little incentive for estimators to use these tools. 
- Currently, BIM-enabled asset tracking is also rarely called for and the incentives for this activity are weak.

\section{Conclusion}

This study has shown that BIM data may be used to assist with estimating. Quantification data need to be exported, (re)structured and moderated with care. This requires estimators to consider different risk areas and to accommodate these in their presentations to clients. However stakeholders find it difficult to visualize the factors that have cost consequences. BIM process hyper-models provide such opportunities by facilitating the integration of contributing disciplines' views, thereby creating a common understanding of costs.

There are additional challenges that estimators face. As with conventional processes, comprehensive guides are required to inform practitioners how to develop and use these models. Rather than applying conventional rules and techniques (which were implemented to ensure the integrity of quantification data and estimating outcomes) the current challenge is how to manage and integrate data. Importantly, BIM facilitates integration and has the potential to enable the views of different practice domains to converge. However, this is outside the scope of this study. It is recommended that further investigations focus on:

- Developing practice guides for process modelling, and the standards for integrating these across different applications and disciplines.

- Communicating the benefits of BIM-enabled estimating to clients so that they more fully understand the professional services provided to them. BIM-enabled services warrant new approaches for valuing the professional services offered by estimators.

- Process models require activities to have logical connections between themselves and the prescribed outcomes. This area requires further empirical analysis.

\section{References}

Abdelkarim, M. 2010, 'BIM, ERP and Field Mobility in Construction - Technology and Strategy in the 21st Century', A keynote presented at the 27th International Conference on Aplications of IT in the AEC Industry, $16-19^{\text {th }}$ November, Cairo, Egypt.

Acharya, N.K., Lee, Y.D., \& Im, H.M. 2006, 'Conflicting factors in construction projects: Korean perspective', Engineering, Construction and Architectural Management, 13 (6), 543-66. doi: http://dx.doi.org/10.1108/09699980610712364

Aje, I.O. (2012), 'The impact of contractors' prequalification on construction project delivery in Nigeria', Engineering, Construction and Architectural Management, 19 (2), 159-72. doi: http://dx.doi.org/10.1108/09699981211206098

Akintoye, A. \& Fitzgerald, E. 2000, 'A survey of current cost estimating practices in the UK', Construction Management and Economics, 18 (2), 161-72. doi: http://dx.doi.org/10.1080/014461900370799

Amor, R. \& Faraj, I. 2001, 'Misconceptions about integrated project databases', Journal of Information Technology in Construction (ITcon), 6 (5), 57-68.

Amor, R., Jiang, Y. \& Chen, X. 2007, 'BIM in 2007 - are we there yet?', Paper presented at the CIB International Conference on applications of IT in Construction (CIB-W78): Bringing ITC Knowledge to work, 26-29 June, Maribor, Slovenia, 159-62.

Aranda-Mena, G., Crawford, J., Chevez, A. \& Froese, T. 2009, 'Building information modelling demystified: does it make business sense to adopt BIM?', International Journal of Managing Projects in Business, 2 (3), 419-34. doi: http://dx.doi.org/10.1108/17538370910971063 
Aranda-Mena, G., Succar, B., Chevez, A., Crawford, J. \& Wakefield, R. 2008, BIM National guidelines and case studies, Melbourne, Australia: Cooperative Research Centres (CRC) for Construction Innovation (2007-02-EP), 1-122.

Ashley, D.B. \& Teicholz, P.M. 1977, 'Pre-Estimate Cash Flow Analysis', Journal of the Construction Division, 103 (3), 369-79.

Ashworth, A. 2010 Cost Studies of Building, 5th ed., Pearson Prentice Hall, Harlow, UK.

Ashworth, A. \& Hogg, K. 2007 Willis's Practice and Procedure for the Quantity Surveyor, 12th ed., Wiley-Blackwell, Oxford, UK.

Bailey, C. 2010, 'The Development of BIM-5D Estimating Capability', Retrieved 31st July, 2011, http://www.ricsamericas.org/files/editor/Development_of_5D_Estimating_Paper_4.pdf

Best, R., de Valence, G., Langston, C. \& Smith, P. 1996, 'Information Technology and evolution of Quantity Surveying profession - future direction', In proceedings of International Construction Information Technology Conference INCIT 96 Proceedings: Bridging the Gap, 18-19 April, Sydney, Australia, 151-55.

Broekmaat, M. 2008, 'The 5D BIM Connection to Estimating', Retrieved July 6, 2010, http://www.vicosoftware.com/blogs/vicos_flying_dutchman/tabid/47083/bid/4451/The-5D-BIM-

Connection-to-Estimating.aspx

Brook, M. 2004 Estimating and Tendering, Elsevier Butterworth-Heinermann, Oxford, UK.

Brook, M. 2008 Estimating and Tendering for construction works, Fourth ed., Elsevier Science and Technology, Oxford, UK.

Cartlidge, D. 2010 Quantity Surveyor's Pocket Book, Reprinted First Edition ed., Kidlington Butterworth-Heinemann, Oxford, UK.

Chou, Jui-Sheng 2011, 'Cost simulation in an item-based project involving construction engineering and management', International Journal of Project Management, 29 (6), 706-17. doi: http://dx.doi.org/10.1016/j.ijproman.2010.07.010

Collier, K. 1974 Fundamentals of construction estimating and cost accounting, Prentice-Hall.

Dean, R.P. \& McClendon, S. 2007, 'Specifying and Cost Estimating with BIM', Retrieved 12th August, 2008, www.architechmag.com/articles/detail.aspx?contentID=3624

Eastman, C., Liston, K., Sacks, R. \& Teicholz, P. 2011 A BIM Handbook: A Guide to Building Information Modeling for Owners, Managers, Designers, Engineers and Contractors, 2nd ed., Wiley, NY.

Geiger, T.S., \& Dilts, D.M. 1996, 'Automated design-to-cost: integrating costing into the design decision', Computer-Aided Design, 28 (6-7), 423-38. doi: http://dx.doi.org/10.1016/00104485(94)00030-1

Gerrard, A.M. 2000 Guide to capital cost estimating, Fourth Edition, Institute of Chemical Engineers (IChemE), Warwickshire, UK.

Goldberg, E.H. 2007, 'Automated Estimating and Scheduling Using BIM (AEC in Focus Column)', Cadalyst (Online Magazine), 24 (9), 45-48.

Gu, N., Singh, V., Taylor, C., London, K., \& Brankovic, L. 2007 'Building information modelling : an issue of adoption and change management', In Pitsis, Tyrone (eds), ICAN conference 2007: Mission Control: Power, knowledge and collaboration in project practice, Australian Institute of Project Management (AIMP), 28 August, Sydney, Australia, 1-12.

Gujarathi, G.P. \& Ma, Y.S. 2011, 'Parametric CAD/CAE integration using a common data model', Journal of Manufacturing Systems, $30 \quad$ (3), $118-32 . \quad$ doi: http://dx.doi.org/10.1016/j.jmsy.2011.01.002

Hardie, M.P., Miller, G., Manley, K. \& McFallan, S. 2005, 'The quantity surveyor's role in innovation generation, adoption and diffusion in the Australian construction industry', Paper presented at the Queensland University of Technology (QUT) Research Week, 4-8 July, Brisbane, Australia, 1-11. 
Harris, F., McCaffer, R. \& Edum-Fotwe, F. 2006 Modern Construction Management, Sixth ed., Blackwell Publishing, Oxford, UK.

Holzer, D. 2007, 'Are you talking to me? BIM alone is not the answer', Paper presented at the Fourth International Conference of the Association of Architecture Schools Australasia Conference, University of Technology Sydney, 27-29 September, Australia, 1-7.

Huang, T., Li, H., Guo, H., Chan, N., Kong, S. \& Skitmore, M. 2009, 'Construction virtual prototyping: a survey of use', Construction Innovation: Information, Process, Management, 9 (4), 420-33.

Hubers, J.C. 2010 IFC-based BIM or Parametric design? In Computing in Civil and Building Engineering, W. Tizani ed., The University of Nottingham, England, 145-47.

Ji, Y., Beetz, J., Bonsma, P., Bisbet, N., Katz, C. \& Borrmann, A. 2011, 'Integration of Parametric Geometry into IFC-Bridge', Retrieved 25 Nov 2014, https://www.academia.edu/2546128/Integration of Parametric Geometry into IFC-Bridge

Kim, S.A., Chin, S., Yoon, S.W., Shin, T.H., Kim, Y.S. \& Choi, C. 2009, 'Automated Building Information Modeling System for Building Interior to Improve Productivity of BIM-based Quantity Take-Off', In Proceedings for the $26^{\text {th }}$ International Symposium on Automation and Robotics in Construction (ISARC), 492-96.

König, M., Beißert, U. \& Bargstädt, H.J. 2007, 'Visual Simulation - An Appropriate Approach To Support Execution Planning In Building Engineering', Paper presented at the 7th International Conference on Construction Applications of Virtual Reality, October 22-23, 189-97.

Lawrence, M., Pottinger, R., Staub-French, S. \& Nepal, M.P. 2014, 'Creating flexible mappings between Building Information Models and cost information', Automation in Construction, 45, 107-18. doi: http://dx.doi.org/10.1016/j.autcon.2014.05.006

Love, P.E.D., Edwards, D.J. \& Han, S. 2011, 'Bad Apple Theory Of Human Error And Building Information Modelling: A Systemic Model For BIM Implementation', Paper presented at the $28^{\text {th }}$ ISARC, Seoul, Korea, 349-54.

Lowe, D. \& Skitmore, M. 1994, 'Experiential learning in cost estimating', Construction Management and Economics, 12 (5), 423-31. doi: http://dx.doi.org/10.1080/01446199400000052

Ma, Z., Wei, Z. \& Zhang, X. 2013, 'Semi-automatic and specification-compliant cost estimation for tendering of building projects based on IFC data of design model', Automation in Construction, 30, 126-35. doi: http://dx.doi.org/10.1016/j.autcon.2012.11.020

McCuen, T. 2009, 'Cost Estimating in BIM: The Fifth Dimension', Retrieved 30th Sept, 2011, http://constructionadvisortoday.com/2009/11/cost-estimating-in-bim-the-fifth-dimension.html

Ogunlana, S. \& Thorpe, A. 1991, 'The nature of estimating accuracy: Developing correct associations', Building and Environment, 26 (2), 77-86. doi: http://dx.doi.org/10.1016/03601323(91)90015-4

Olatunji, O.A. 2012 'The impact of building information modelling on estimating practice: analysis of perspectives from four organizational business models', Doctor of Philosophy Dissertation, University of Newcastle, Newcastle, Australia.

Olatunji, O.A. 2014, 'Views on building information modelling, procurement and contract management', Proceedings of the ICE-Management, Procurement and Law, 167 (3), 117-26.

Olatunji, O.A. \& Sher, W. Chapter VII 2010, 'A Comparative Analysis of 2D Computer-Aided Estimating (CAE) and BIM Estimating Procedures', J. Underwood \& U.E. Isikdag (eds.), Handbook of research on building information modeling and construction informatics: concepts and technologies, 170-89

Olatunji, O.A., \& Sher, W. 2014, 'Activities in geometric 3D CAD estimating', Journal of Financial Management in Property and Construction, Accepted for publication November 2014.

Olatunji, O.A., Sher, W.D., \& Gu, N. 2010, 'Building Information Modeling and Quantity Surveying Practice - whatever you thought, think again', Emirate Journal of Engineering Research (EJER), 15(1), 67-70. 
Peterson, S. \& Dagostino, F.R. 2010 Estimating in Building Construction 7th ed. Pearson Higher Ed., USA.

Pratt, D.J. 2011 Fundamentals of Construction Estimating Third ed. Delmar Cengage Learning, Cliffton Park, NY.

Pučko, Z., Šuman, N. \& Klanšek, U. 2014, 'Building Information Modeling Based Time And Cost Planning In Construction Projects', Organization, Technology \& Management in Construction, An International Journal, 6 (1), 958-71.

RICS 2014, 'Building Cost Information Service', Retrieved 25 June 2014, http:// www.rics.org/au/knowledge/bcis/about-bcis/bcis-overview/

RIBA 2013, 'Plan of Work stages', Retrieved 28th October 2014 http://www.architecture.com/Files/RIBAProfessionalServices/Practice/RIBAPlanofWork2013Template. pdf

Sabol, L. 2008, 'Challenges in Cost Estimating with Building Information Modeling. Design and Construction Strategies', Retrieved $8^{\text {th }}$ December 2010, http://www.dcstrategies.net/news.php

Samphaongoen, P. 2010, 'A Visual Approach to Construction Cost Estimating' Master's Theses, Marquette University, Milwaukee, Wisconsin, 1-113.

Sattenini, A., Azhar, S. \& Thuston, J. 2011, 'Preparing a building information model for facility maintenance and management', Paper presented at the $28^{\text {th }}$ ISARC Conference, Seoul, Korea, 15055.

Sattenini, A. \& Bradford, R.H. 2011, 'Estimating with BIM: A survey of US construction companies', Paper presented at the $28^{\text {th }}$ ISARC Conference, Seoul, Korea, 564-69.

Seeley, I.H. \& Murray, G.P. 2001 Civil Engineerng Quantities, Sixth Edition ed. Palgrave Macmillan.

Seeley, I.H. \& Winfield, R. 1998 Building Quantities Explained (Building \& Surveying) 5th ed. Palgrave Macmillan.

Sher, W. 1982, 'Computer-aided measurement - a new development', South African Builder, 61(8), 41-45.

Sher, W. 1991 'A review of construction computing in South Africa in 1991', R. Schloss (ed.), Merkel's Builders' Pricing and Management Manual, Thomsons Publications (RSA), 1227-31.

Sher, W. 1996 Computer-aided Estimating - A guide to Good Practice, Addison Wesley Longman Limited, Harlow.

Skitmore, M. 1990 'Which estimating technique?', Paper presented at the The 11th International Cost Engineering Congress and 6th Association Francais des Ingenieurs et Techniciens D'estimation de Planification de Projets Annual Meeting, Paris, France.

Skitmore, M. \& Wilcock, J. 1994, 'Estimating processes of smaller builders', Construction Management and Economics, 12, 139-54. doi: http://dx.doi.org/10.1080/01446199400000020

Smith, M. \& Skitmore, M.R. 1991, 'Automatic BQ Pricing', Paper presented at the Transactions AACE 35th Annual Meeting, Seattle, Washington.

Succar, B. 2009, 'Building information modelling framework: A research and delivery foundation for industry stakeholders', Automation in Construction, 18 (3), 357-75. doi: http://dx.doi.org/10.1016/j.autcon.2008.10.003

Tiwari, S., Odelson, J., Watt, A. \& Khanzode, A. 2009, 'Model Based Estimating to Inform Target Value Design', Retrieved 11 January 2014, http://www.aecbytes.com/buildingthefuture/2009/ ModelBasedEstimating.html

Underwood, J. \& Alshawi, M. 1997, 'Data and Process Models for the Integration of Estimating and Valuation', Microcomputers in Civil Engineering, 12, 369-81.

Velasquez, J.D., Lara, M.A. \& Nof, S.Y. 2008, 'Systematic resolution of conflict situations in collaborative facility design', International Journal of Production Economics, 116 (1), 139-53. 
Vozzola, M., Cangialosi, G. \& Lo Turco, M. 2009, 'BIM Use in the Construction Process', Paper presented at the Management and Service Science, MASS '09 International Conference, 20-22 September, Wuhan, 1-4.

Yan, W. 2008, 'Environment-Behavior Simulation From CAD to BIM and Beyond', Paper presented at ACADIA conference, Minneopolis, October 16-19, 478-85.

Yum, K.K., Froese, T., Aranda-Mena, G., Sher, W. \& Goodman, N. 2008, 'Model-based estimating for concrete bridges: a feasibility study', K. Brown, K. Hampson, P.S. Brandon \& J. Pillay (eds.), Clients driving construction innovation, Benefiting from innovation, Brisbane, Cooperative Research Centre for Construction Innovation, 101-09.

Zhiliang, M., Zhenhua, W., Wu, S. \& Zhe, L. 2011, 'Application and extension of the IFC standard in construction cost estimating for tendering in China', Automation in Construction, 20 (2), 196-204. 